\title{
Metode Pengering Gabah Aliran Massa Kontinu Sebagai Pengering Alternatif Pada Musim Penghujan Dengan Sumber Energi Dari Cahaya Lampu Mono Kromatis
}

\author{
Nusyirwan \\ Jurusan Teknik Mesin, Fakultas Teknik Universitas Andaas, Limau Manis, Pauh, Padang 25163, Indonesia
}

INFORMASI ARTIKEL

Sejarah Artikel:

Diterima Redaksi: 06 Februari 2018

Revisi Akhir: 22 Maret 2018

Diterbitkan Online: 26 April 2018

\section{KATA KUNCI}

gabah

mono kromatis

ultraviolet

pengering

KORESPONDENSI

E-mail: nusyirwan@ft.unand.ac.id

\begin{abstract}
A B S T R A C T
In the rainy season, rice grain from the harvesting field cannot be dried properly. This condition is due to sunlight being blocked up by the cloud therefore the sunlight intensity on the earth surface is small. As a consequence many farmers become loss because this low quality rice is sale at a lower price. To overcome the above problems, it is necessary to make a dryer that not directly depend on the solar energy. In this research, a method for rice drying using light from monochrome lamp is proposed. The dryer consist of a silinder-shaped container which is equipped whith a stirer that can be adjusted according to the desired speed. In the drying chamber, hot air that regulated in the drying room is produced by incandescent lamp. The drying result obtained from this dryer using $40 \mathrm{rpm}$ rotation speed reaches an absolute dry percentage of rice at equivalent of $14 \%$. While for stirrer rotation $50 \mathrm{rpm}$ and $60 \mathrm{rpm}$ the drying percentage is $8 \%$ and $5 \%$. From these results, it can be concluded that the best condition for the drying process is obtained for stirrer rotation speed $40 \mathrm{rpm}$.
\end{abstract}

\section{PENDAHULUAN}

\subsection{Latar Belakang}

Seiring dengan pertambahan jumlah penduduk Indonesia yang semakin cepat mengakibatkan peningkatan kebutuhan pangan terutama beras semakin meningkat. Faktor yang kontroversial adalah jumlah lahan persawahan untuk pertanian di Indonesia yang setiap tahun semakin berkurang. Permasalahan lain yang timbul adalah iklim dengan kelembaban tinggi menyebabkan panen sering rusak akibat jamur karena kurangnya cahaya matahari pada musim pada musim penghujan untuk pengeringan gabah. Proses pengeringan padi tidak dapat berjalan secara optimal sehingga menyebabkan pembusukan dan penurunan kualitas beras. Kondisi ini tidak bisa dibiarkan agar para petani tidak mengalami kendala untuk menjemur gabah pada musim hujan tersebut. Untuk itu bantuan teknologi sangat diperlukan untuk mengatasi hal tersebut.

Beberapa cara penjemuran telah dilakukan baik secara tradisional yaitu cara penjemuran dengan menggunakan lantai penjemuran (hamparan) dengan berbagai bentuk lantai yang ditambah alas [1]. Dengan metode ini gabah dihamparkan pada tembok yang datar dengan menggunakan alas seperti tikar plastik, kemudian pada waktu tertentu akan dibalik-balik agar pengeringan padi merata. 
Dengan berkembangnya teknologi pengeringan gabah dilakukan secara mekanisasi seperti pengeringan statik seperti mekanisme tray dryer( dengan rak bertingkat)[2]. Lambat laun pengeringan dapat dilakukan dengan sistem kontinu dan gabah yang dikeringkan dapat diproses dengan cepat [3]. Peralatan pengering yang telah diteliti dapat mengeringkan gabah secara kontinu dengan sumber panas tidak lagi dari cahaya matahari tetapi dari bahan bakar seperti batok kelapa ,sekam padi dan bio massa lainnya. [4]. Dengan peralatan pengering seperti ini cahaya matahari tidak diperlukan lagi karena ada sumber panas dari bahan bakar. Alat pengering tersebut dapat digunakan bila panen gabah terjadi pada musim penghujan.

Salah satu yang dikaji dalam penelitian ini adalah wadah pengering dari silinder yang dilengakapi dengan agitator (pengaduk). Peralatan pengering dengan sumber bahan bakar dari batok kelapa dan sekam padi akan diganti dengan suber cahaya dari lampu mono kromatis. Karena bahan bakar dari batok kelapa ini menghasilkan polusi udara dan pans yang dihasikan sulit diatur, sehingga gabah yang dihasikan tidak merata kualitasnya. Sehingga suber energi panas kan diganti dengan cahay dari lampu mono kromatis yang dapat diatur berapa panas yang diinginkan. Lampu mono kromatis adalah jenis lampu yang mempunyai satu panjang gelombang tertentu misal ultraviolet atau imfrared. Lampu monokromatis ini dapat menghasilkan cahaya dengan panjang gelombang tertentu. Cahaya yang dihasilkan dapat meningkatkan temperatur udara sebagai sumber energi panas untuk proses pengeringan [5].

\subsection{Tujuan}

Tujuan yang diharapkan dapat tercapai dari penelitian ini adalah :

1 Menentukan besarnya temperatur udara yang mengalir keruangan pengering yang berasal dari energi yang dihasilkan dari lampu monokromatis .

2 Menentukan laju pengeringan gabah yang dapat dihasilkan dari suatu peralatan pengering skala laboratorium terhadap pengaruh variasi kecepatan pengaduk terhadap produk gabah yang dihasilkan.

\subsection{Manfaat}

Melalui pembuatan suatu peralatan pengering skala laboratorium ini yang sumber bahan bakarnya berasal dari lampu cahaya monokromatis penelitian ini dapat dikembang untuk dasar pengembangan dari suatu peralatan pengering dalam ruangan tertutup dengan sumber energi yang bisa dikontrol dan ramah lingkungan tidak berasap dan tidak menimbulkan polusi. Kajian lebih dalam yang dalam setelah penelitian ini adalah mengkaji jumlah energi yang diperlukan untuk membangkitkan sumber cahaya dari lampu monokromat dibandingkan dengan biaya energi dari bahan bakar seperti kebanyakan pengering yang telah banyak beredar dipasaran.

\subsection{Ruang Lingkup Pembahasan}

Dalam penelitian ini, dimensi kolektor pemanas dengan luas $60 \mathrm{~cm} \times 60 \mathrm{~cm}$ dengan jumlah aliran udara $0,025 \mathrm{~kg} / \mathrm{s}$ dengan dimensi drum pemanas adalan panjang $1,5 \mathrm{~m}$ dan diameter $45 \mathrm{~cm}$. Aliran massa pengering dapat divariasikan dari $0,01 \mathrm{~kg} / \mathrm{s}$ sampai $0,1 \mathrm{~kg} / \mathrm{s}$. Lampu monokromatis dari lampu halogen dengan daya 75 wat dan dengan peralatan penukar panas jenis aliran campur antara material dan udara panas. Kecepatan aliran udara dapat diatur dengan mengatur kecepatan blower yang dipasang didepan pipa saluran pemanas udara yang berasal dari kolektor kaca plat datar dan pipa udara yang dipasang didalam kolektor dan yang disolasi dari dari ligkungan agar jumlah panas tidak berkurang.

\section{TINJAUAN PUSTAKA}

\subsection{Radiasi Lampu Pijar}

Lampu mono kromatis adalah jenis lampu yang mempunyai satu panjang gelombang tertentu misal ultraviolet atau imfrared. Lampu monokromatis ini dapat menghasilkan cahaya dengan panjang gelombang tertentu. Cahaya yang dihasilkan dapat meningkatkan temperatur udara sebagai sumber 
energi panas untuk proses pengeringan [2]. Salah satu kelebihan dari cahaya yang dapat dihasilkan dari cahaya monokromatis adalah dapat ditentukan efek kwalitas material yang dihasilkan ,karena sumber energi yang bisa diatur agar material tidak terlalu kering dan retak [4]. Misal cahaya ultraviolet bisa meniru caha yang dipancarkan oleh cahaya matahari dalam ruangan tertutup.

Radiasi adalah adalah pancaran energi melalui suatu materi atau ruang dalam bentuk panas, partikel, gelombang elektromagnetik dan cahaya dari suatu sumber pemancar energi atau sumber suatu cahaya. Radiasi yang ada pada bumi semuanya berasal dari radiasi energi matahari yang berasal dari proses thermonuklir yang terjadi pada inti matahari. Energi radiasi matahari terdiri dari sinar dan gelombang elektromagnetik. Spektrum radiasi matahari terdiri dari dua yaitu spektrum sinar gelombang pendek danspektrum sinar gelombang panjang. Yang termasuk sinar gelombang pendek adalah sinar $\mathrm{x}$, sinar gamma, sinar ultra-violet. Sedangkan sinar gelombang panjang adalah sinar imfr-ared. Jumlah radiasi matahari yang sampai kebumi tergantung terhadap posisi jauh dekatnya permukaan bumi terhadap matahari dan sudut datangnya radiasi terhadap suatu permukaan di bumi. Radiasi lain bisa juga bersumber dari radio aktif, pembakaran temperatur tinggi dan pancaran cahaya dari lampu pijar atau kawat panas. Berdasarkan hal tersebut jika suatu radiasi matahari berkurang untuk suatu tujuan tertentu dapat digantikan dari sumber lain misalnya dari lampu pemanas dan sebagainya. Hukum Stevan-Boltzmann menyatakan hubungan antara radiasi yang dipancarkan suatu benta pada suhu tertentu dengan emisivitas dinyatakan sebagai berikut;

$$
P=e \sigma A T^{4}
$$

Persamaan ini menyatakan hubungan antara emisivitas bahan, luas penampang bahan dan konstanta Stefan_Boltzmann $\sigma$ sebesar 5,6703 x $10^{-8} \mathrm{~W} .\left(\mathrm{m}^{-2} \mathrm{~T}^{4}\right)$. Pada lampu pijar terdapat sebuah filamen dari kawat wolfram yang memiliki nilai tahan R, bila filamen dialiri arus listrik sebesar I pada jumlah waktu tertentu akan terbentuk dan terkumpul panas pada filamen tersebut dan panas ini akan berubaha menjadi cahaya tampak. Tahanan dari kawat woltfram yang berfungsi sebagai pengumpul energi sebesar

$$
R=e \sigma \mu L
$$

Edward(1879) menyelidiki suatu percobaah Hukum Stefan-Boltzmann dengan membuat suatu rangkain JembatamWheatstone dengan bola lampu wat rendah bahwa penyerapanenergi radiasi filamen oleh arus konveksi dalam bolalampu bisa diabaikan. Prasad (1976) melakukan hubungan antara hambatan R,dan temperatur Tpadasuatu lampu pijar akan memenuhi suatu persamaan;

$$
R=R_{273}\left(\frac{T}{273}\right)^{1 / 2}
$$

Dow(1952)menyatakan hubungan tahanan kawat woltfram dengan temperatur yangterbentuk adalah $R \infty T^{1 / 2}$. Bila digunakan untuk perlaukan lampu pijar lain secara umum akan berlaku persamaan

$$
P=\alpha_{0} T^{N}
$$

Persamaan datas berlaku bila $\alpha_{0}=e \sigma A$ dan angka 4 pada konstanta StefanBoltzman akan dicari dari hasil percobaan. Daya listrik yang dibangkitkan antara kuat arus dan tahanan kawat woltfram adalah sebagai berikut;

$$
P=I^{2} R
$$

Dari persamaan (4) dan persamaan (5) berlaku hubungan

$$
I^{2} R=\alpha_{0} T^{N}
$$

Rangkaian lampu pijar untuk menghasilkan suatu radiasi panas dapat diperlihatkan pada gambar 2.1. Pada gambar ini pengaturan besar radiasi dapat 
ditentukan oleh daya lampu yang dikehendaki sebagai fungsi kuat arus dan voltase lampu pijar.

\subsection{Teori Optik Untuk Cahaya}

Bila radiasi yang dipancarkan dapat merambat dengan sangat cepat maka prinsip optik akan berlaku pada rambatan radiasi lampu pijar.

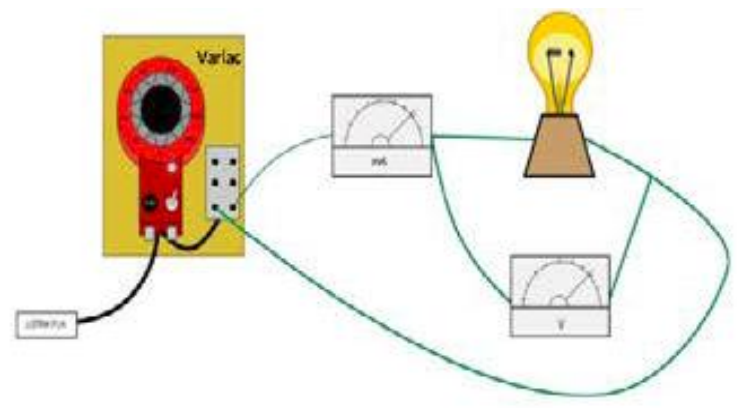

Gambar 1. Rangkaian Lampu Pijar untuk Radiasi panas [3]

Menurut hukum optik cahaya akan memantul lebih merata pada bidang datar dibanding benda yang tidak rata Pada bidang datar akan menyebabkan suhu merata di segala titik.Untuk itu kita perlu suatu kolektor yang dilengkapi dengan bidang pemantul dari plat logam yang datar dan diharapkan dapat memantul cahaya kesemua bidang pemanas secara merata sehingga ruang pemanas dapat mencapai suhu yang dikehendaki dengan waktu yang tidak terlalu lama. [5].

Efisiensi lampu atau dengan kata lain disebut efefikasi luminus adalah nilai yang menunjukan besar efisiensi pengalihan energi listrik ke cahaya dan dinyatakan dalam satuan lumen per Watt. Untuk lampu pijar hanya $10 \%$ saja yang ditransfer menjadi energi cahaya tampak sebagai penerangan sisanya $85 \%$ diubah menjadi radiasi kemudian lebih kurang $5 \%$ lagi menjadi energi losses [3]. Dengan harga yang besar ini lampu pijar salah satu bisa dimanfaatkan sebagai sumber energi untuk pemanas dan pengering.

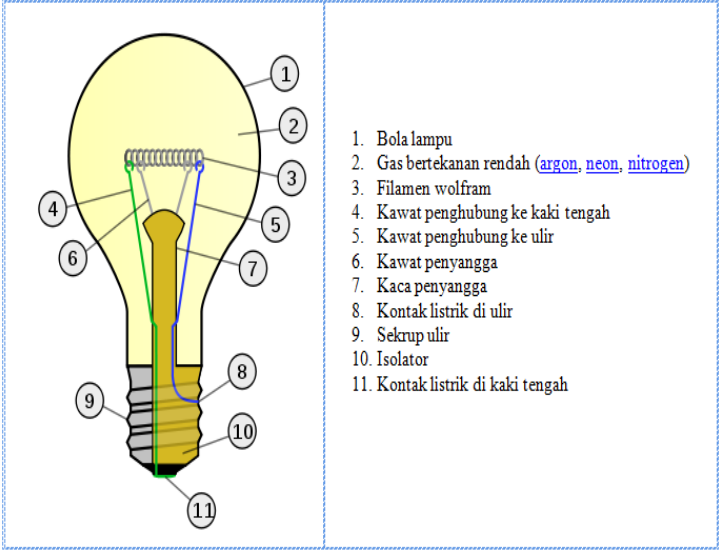

Gambar 2. Komponen lampu pijar [3]

Pada tegangan 120 volt keluaran cahaya lampu 100 wat adalah 1750 lumen, maka efisiensinya adalah 175 lumen/Watt sedangkan untuk tegangan 230 volt lampu 100 Watt tersebut adalah 1380 lumen dengan efisiensi 13,8 lumen/Watt. Untuk lampu lmpu yang menghasilkan cahaya putih ideal 242,5 lumen/Watt dan cahaya hijau-kuning 683 lumen/Watt cahaya ini sangat peka terhadap mata manusia[3].

Lampu infrared merupakan lampu pijar yang kawat pijarnya bersuhu diatas $\pm 2500^{\circ} \mathrm{K}$ hal inilah yang menyebabkan sinar imfrared lebih banyak dipancarkan dari lampu pijar biasa. Oleh sebab itu lampu imfrared banyak digunakan sebagai pemanas pada industri. Pemanasan dengan sinar imframerah adalah dimana energi imfrared menyerang objek dengan energi elektromagnetik diatas suhu mutlak diatas $-273^{\circ} \mathrm{K}$ atau diatas suhu mutlak. Maka oleh sebab itu lampu imfrared banyak digunakan sebagai pemanas dan pemanggang makanan karena cahaya lampu ini diubah $90 \%$ menjadi panas dan hanya $10 \%$ saja yang menjadi cahaya [4]

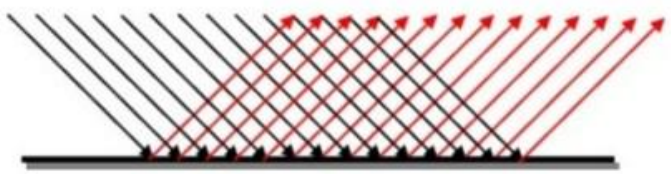

Gambar 3. Cahaya datang dan pantulannya terhadap permukaan datar[3] 


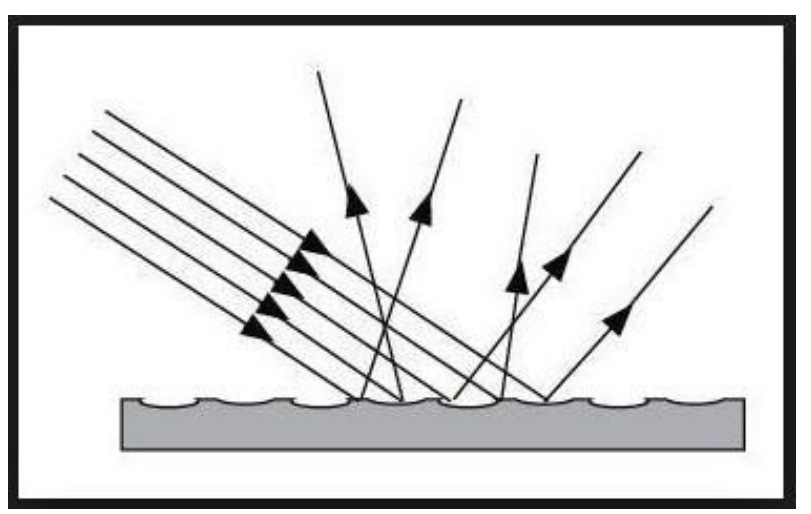

Gambar 4. Caya datang dan pantulannya terhadap permukaan tidak datar[3]

\subsection{Peralatan Pengering}

Pada Gambar 5 s/d 8 diperlihatkan peralatan yang digunakan pada pengering, peralatan ini terdiri atas kolektor plat, wadah pengering dan kolektor lampu pijar.

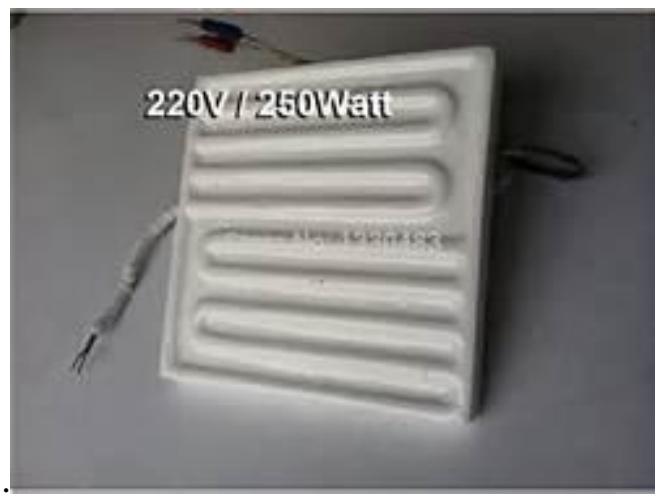

Gambar 5. Alat Pemanas udara kolektor Plat logam[5]

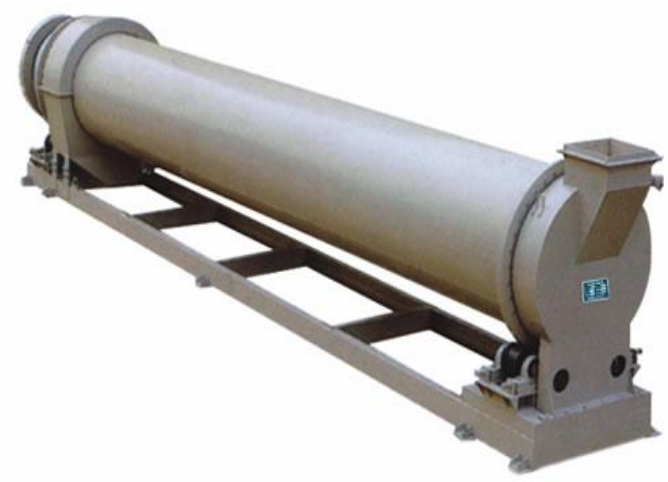

Gambar 6. Wadah Pengering berbentuk drum.[5]

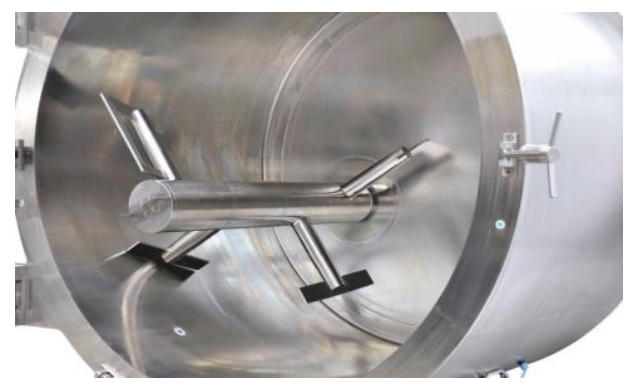

Gambar 7. Penampang Wadah Pengering berbentuk drum dan pengaduk putar[3].

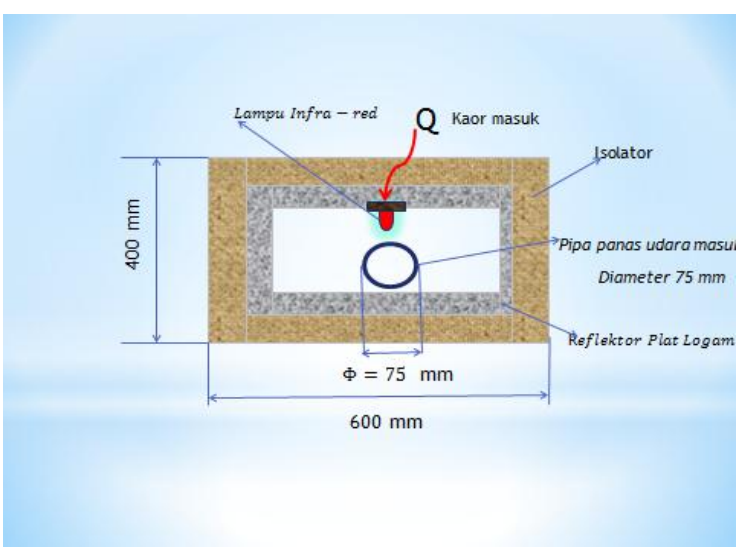

Gambar 8. Kolektor Lampu Pijar[5]

Kadar air adalah perbandingan antara berat air di dalam gabah terhadap berat gabah yang mengandung air tersebut menurut [4].

$$
K_{w}=\frac{m_{w}}{m_{w}+m_{d}}
$$

Untuk menghitung massa air yang diuapkan, dapat digunakan persamaan berikut :

$$
\left.\Delta m_{w}=\frac{m\left(K_{0}-K_{1}\right)}{1-K_{1}}\right)
$$

Keterangan : $\Delta m_{w} \quad$ :massa air yang diuapkan Laju penguapan air sangatlah berpengaruh dalam proses pengeringan, yang menggambarkan bagaimana kecepatan pengeringan tersebut berlangsung. Laju penguapan dinyatakan dengan berat air yang diuapkan persatuan waktu (disaat kadar air $\pm 14 \%$ ). Dapat dihitung menggunakan persamaan berikut :

$$
W_{d o t}=\frac{\Delta m_{w}}{T}
$$




\section{METODE PENGUJIAN}

Dalam pengujian, kadar air di dalam gabah diasumsikan sama dengan jumlah massa gabah yang hilang akibat proses pengeringan. Jumlah massa gabah yang diumpankan adalah sebanyak 10 $\mathrm{kg}$ dan dialirkan dengan merata kedalam wadah pengering. Lamanya siklus pengeringan adalah selama 60 menit untuk siklus pertama. Semua sampel yang keluar dari peralatan pengering akan ditimbang selama periode ini dan beratnya akan dicatat. Setelah itu akan diumpankan kembali kedalam wadah pengering untuk periode siklus kedua dan akan dilakukan seperti siklus sebelumnya.

Prosedur pengujian dimulai dengan menghidupkan lampu pinjar sebagai pemanas sampai kolektor menunjukan temperatur konstan $30{ }^{\circ} \mathrm{C}$ selama lebih kurang 15 menit, kemudian dilakukan langkah-langkah sebagai berikut :

(1) Persiapkan alat pengering dan padi yang akan dikeringkan sebanyak $10 \mathrm{~kg}$.

(2) Atur putaran motor menggunakan slide regulator dan ukur putaran poros pengaduk hingga kecepatan $40 \mathrm{rpm}, \quad 50 \mathrm{rpm}$ dan $60 \mathrm{rpm}$ menggunakan tachometer.

(3) Nyalakan blower dan ukur temperatur untuk udara panas masuk dan keluar menggunakan thermometer.

(4) Masukkan padi dari daerah pertama kedalam hopper inlet, kemudian buka pengatur masukan secara perlahan, setelah padi masuk seluruhnya, tutup kembali pengatur masukan catat temperatur masuk dan keluar padi

(5) Hitung waktu padi berada di dalam drum selama 60 menit menggunakan stopwatch.

(6) Buka pengatur keluaran pada hopper outlet secara perlahan, setelah padi keluar seluruhnya tutup kembali pengatur keluaran.

(7) Timbang berat padi menggunakan timbangan digital kemudian catat hasil penurunan massanya. (8) Lakukan prosedur 4-7 untuk padi dari daerah yang berbeda dengan penambahan waktu 10 menit tiap proses berikutnya hingga masa akhir padi hampir tidak mengalami penurunan (massa padi telah konstan).

\subsection{Pengujian kadar kekeringan gabah}

Pengujian ini dilakukan untuk mendapatkan karakteristik pengeringan padi yang baik dalam wadah pengering dengan bantuan mekanisme pengaduk putar. Pengaduk putar ini berfungsi untuk mengaduk massa gabah dapat tercampur secara merata dan mengalir keluar wadah pengering secara kontinu. Proses ini lakukan untuk putaran pengaduk yang berbeda untuk dilakukan perbandingan waktu pengeringan dengan putaran masing-masing pengaduk.

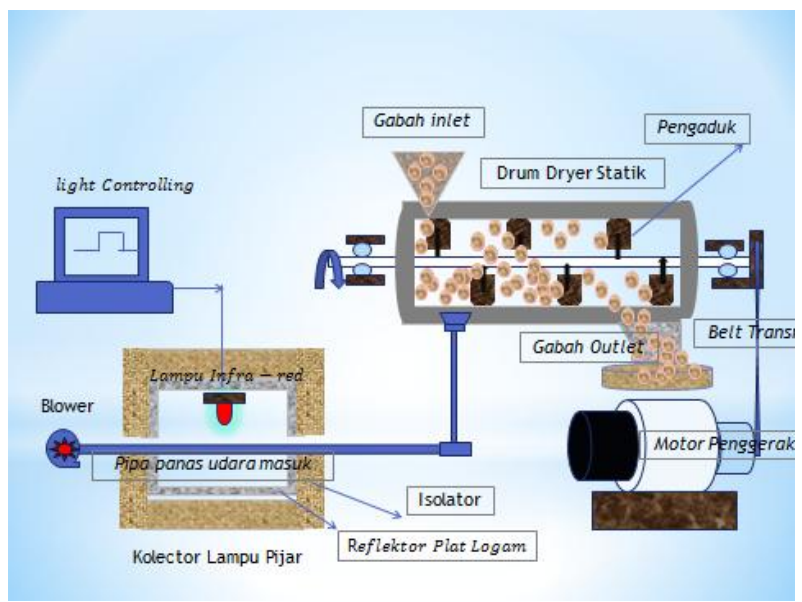

Gambar 9. Peralatan Pengering

Prosedur pengujian adalah sebagai berikut :

(1) Persiapkan padi sebanyak $10 \mathrm{~kg}$ dan dengan lampu pijar 200 watt sampai ditunjukan temperatur yang konstan.

(2) Atur putaran motor menggunakan slide regulator dan ukur putaran poros pengaduk hingga kecepatan 40rpm menggunakan tachometer.

(3) Hidupkan blower dan ukur temperatur di dalam drum hingga mencapai kisaran $60{ }^{\circ} \mathrm{C}$ menggunakan thermometer.

(4) Masukkan padi tersebut kedalam hopper inlet.

(5) Hitung waktu padi berada di dalam drum selama 60 menit menggunakan stopwatch.

(6) Buka pengatur keluaran pada hopper outlet secara perlahan. 
(7) Timbang berat padi menggunakan timbangan digital kemudian catat hasilnya.

(8) Lakukan prosedur 4-7 untuk padi yang sama dengan penambahan waktu 60 menit tiap proses berikutnya hingga waktu pengeringan seluruhnya mencapai 60 menit.

(9) Lakukan prosedur 4-8 untuk kecepatan 50 rpm dan $60 \mathrm{rpm}$ dengan massa padi yang lain dengan prosedur yang sama. Setiap pengujian ini harus mengacu pada standar[ SNI No. 4512.1 TAN-1998].

\section{2. $\quad$ Alat Ukur}

1. Speed Kontrol Motor digunakan untuk mengatur kecepatan pengaduk sesuai dengan yang diinginkan

2. Timbangan Digital digunakan untuk menimbang produk hasil pengeringan

3. Stopwatch digunakan untuk mencatat waktu pengeringan

4. Tachometer digunakan untuk mencatat putaran pengaduk

5. Thermometer digunakan untuk mencatat waktu periode pengeringan

6. Gelas Ukur digunakan untuk mencatat volume gabah hasil produk

\section{HASIL DAN PEMBAHASAN}

Pengurangan massa gabah pada waktu pengeringan adalah sama dengan jumlah massa air yang dipindahkan ke udara panas. Panjang wadah pengering adalah $180 \mathrm{~cm}$ dengan jarak $30 \mathrm{~cm}$ dipasang termometer untuk memantau temperatur gabah dan temperatur udara panas. Pada Tabel 1 diperlihatkan hubungan antara temperatur(T) pada pengering, voltase(V) dan kuat arus (I) dari lampu pijar yang digunakan dalam pengujian. Gambar 10 menunjukkan plot hubungan antara $\mathrm{T}, \mathrm{V}$ dan $\mathrm{I}$ pada pengering.

Tabel 1. Hubungan antara T dan V serta I

\begin{tabular}{rrcrr}
\hline $\begin{array}{c}\mathrm{V} \\
(\text { Volt })\end{array}$ & $\begin{array}{c}\mathrm{I} \\
(\text { Amper })\end{array}$ & $\begin{array}{c}\mathrm{R} \\
(\mathrm{Ohm})\end{array}$ & $\begin{array}{c}\mathrm{P} \\
(\text { watt })\end{array}$ & \multicolumn{1}{c}{$\begin{array}{c}\mathrm{T} \\
\left({ }^{\circ} \mathrm{C}\right)\end{array}$} \\
\hline 10 & 0.10 & 100.00 & 1.0 & 30.2
\end{tabular}

$\begin{array}{rrrrr}20 & 0.21 & 95.23 & 4.2 & 30.8 \\ 30 & 0.31 & 96.77 & 9.3 & 31.9 \\ 40 & 0.33 & 121.21 & 13.2 & 32.6 \\ 50 & 0.37 & 135.14 & 18.5 & 33.7 \\ 60 & 0.39 & 153.85 & 23.4 & 34.7 \\ 70 & 0.40 & 175.00 & 28.0 & 35.6 \\ 80 & 0.43 & 186.05 & 34.4 & 36.9 \\ 90 & 0.44 & 204.54 & 39.6 & 37.9 \\ 100 & 0.46 & 217.39 & 46.0 & 39.2 \\ 110 & 0.47 & 234.04 & 51.7 & 40.3 \\ 120 & 0.48 & 250.00 & 57.6 & 41.5 \\ 130 & 0.42 & 309.52 & 54.6 & 40.9 \\ 140 & 0.41 & 341.46 & 57.4 & 41.5 \\ 150 & 0.39 & 384.61 & 58.5 & 41.7 \\ 160 & 0.37 & 432.43 & 59.2 & 41.8 \\ 170 & 0.31 & 548.38 & 52.7 & 40.5 \\ 180 & 0.29 & 620.69 & 52.2 & 40.4 \\ 190 & 0.28 & 678.57 & 53.2 & 40.6 \\ 200 & 0.29 & 689.65 & 58.0 & 41.6 \\ 220 & 0.27 & 814.81 & 59.4 & 41.9\end{array}$

Pengujian dibagi dalam dua siklus. Satu periode siklus adalah selama 60 menit.

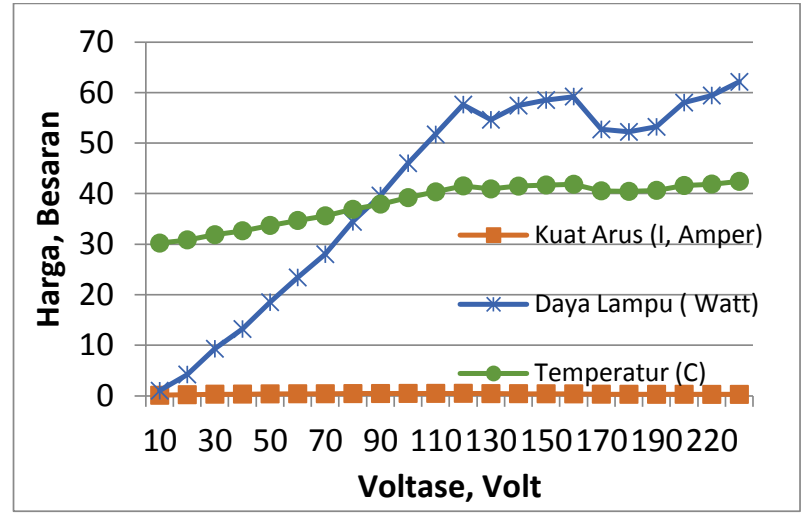

Gambar 10. Hubungan daya, sebagai fungsi, kuat arus, dan Voltase pada lampu pijar.

Dari Gambar 10 terlihat bahwa temperatur yang dihasilkan pada ruang pemanas (kolektor pemanas) berharga konstan setelah 130 Volt dengan kuat arus minimal 0,47 Amper. 


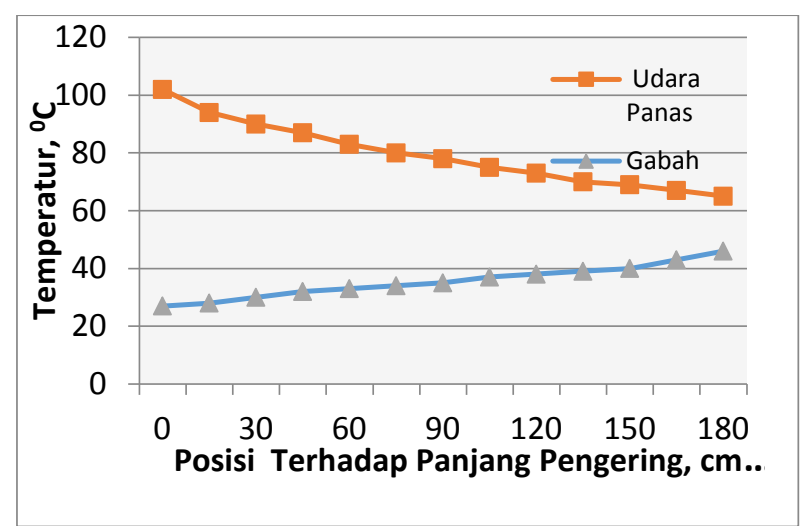

Gambar 11. Grafik Temperatur Massa Gabah terhadap panjang pengerin Pada Siklus 1

Pada Gambar 11 diperlihatkan hubungan antara posisi di dalam pengering terhadap temperatur udara panas dan gabah. Dari Gambar 11 dapat terlihat bahwa temperatur udara masuk $108{ }^{0} \mathrm{C}$ akan turun menjadi $62{ }^{0} \mathrm{C}$ karena akan diambil oleh gabah. Sedangkan temperatur gabah meningkat dari $26^{\circ} \mathrm{C}$ menjadi $42^{\circ} \mathrm{C}$. Dari hasil ini dapat digambarkan terjadi pemindahan energi panas dari udara panas ke gabah yang basah dan mengakibatkan suhu gabah meningkat dan akibatnya sejumlah uap air dapat dilepaskan keudara bebas. Pengeringan dapat berlangsung dengan baik.

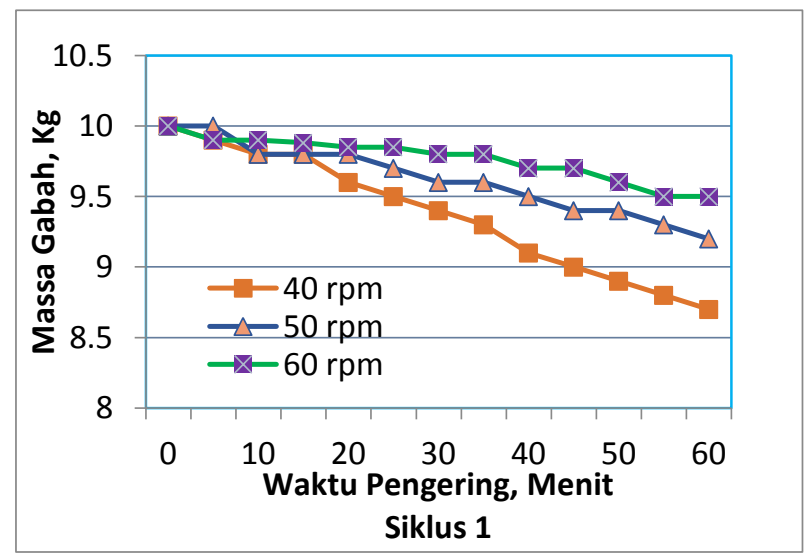

Gambar 12. Grafik Penurunan Massa Gabah terhadap Waktu Pengeringan Pada Siklus 1

Hubungan antara kecepatan putar stirrer terhadap massa gabah diperlihatkan pada Gambar 12. Dari Gambar 12 dapat terlihat bahwa pengeringan yang terbaik diperoleh saat putaran $40 \mathrm{rpm}$ dimana massa gabah turun dari $10 \mathrm{~kg}$ menjadi $8,6 \mathrm{~kg}$ atau
$14 \%$ dari massa air yang ada dalam gabah. Sedangkan untuk putaran $50 \mathrm{rpm}$ berat gabah turun $9,2 \mathrm{~kg}$ hanya $8 \%$ massa air yang dapat dipindahkan ke udara dan putaran $60 \mathrm{rpm}$ hanya 9,5 $\mathrm{kg}$ hanya $5 \%$ dari massa air yang dapat dipindahkan ke udara. Dari hasil ini dapat ditarik kesimpulan bahwa putaran pengaduk yang terbaik untuk peralatan pengering ini adalah pada $40 \mathrm{rpm}$.

\section{KESIMPULAN DAN SARAN}

Dari hasil pengujian diperoleh besarnya parameter sumber energi listrik minimal untuk ruang pemanas adalah kuat arus minimal pada lampu pijar adalah 0,47 Amper dan voltase minimal dari lampu pijar adalah 130 Volt .Temperatur udara masuk $108{ }^{0} \mathrm{C}$ akan turun menjadi $62{ }^{\circ} \mathrm{C}$ karena akan diambil oleh gabah. Sedangkan temperatur gabah meningkat dari $26^{\circ} \mathrm{C}$ menjadi $42^{\circ} \mathrm{C}$, telah terjadi pemindahan energi panas dari udara panas ke gabah yang basah dan mengakibatkan suhu gabah meningkat dan akibatnya sejumlah uap air dapat dilepaskan keudara bebas. Pengeringan dapat berlangsung dengan baik.

Pengeringan yang terbaik adalah massa gabah turun dari $10 \mathrm{~kg}$ menjadi $8,6 \mathrm{~kg}$ untuk putaran 40 rpm atau massa air yang lepas ke udara $14 \%$. Sedangkan untuk putaran $50 \mathrm{rpm}$ berat gabah turun 9,2 $\mathrm{kg}$ atau jumlah air yang lepas keudara $8 \%$ dan putaran $60 \mathrm{rpm}$ hanya $9,5 \mathrm{~kg}$ jumlah massa air yang dilepas keudara sebanyak $5 \%$. Dari hasil ini dapat ditarik kesimpulan bahwa putaran pengaduk yang terbaik untuk peralatan pengering ini adalah pada $40 \mathrm{rpm}$.

\section{UCAPAN TERIMA KASIH}

Penelitian ini dibiayai oleh dana DIPA fakultas Teknik Unand tahun 2016. Ucapan terima kasih kami sampaikan kepada Dekan Fakultas Teknik dan Ketua Jurusan Teknik Mesin universitas andalas yang memberikan bantuan moril dan material untuk berjalannya proses penelitian ini. 


\section{DAFTAR PUSTAKA}

[1] S. Mulyo, "Prospect of Rice Production and Food Security in East Asia, Di dalam Peningkatan Daya Saing Beras Nasional Melalui Perbaikan Kualitas," Lokakarya Nasional. Jakarta: 13-14 September 2006. Kerjasama Perum BULOG dengan FATETA IPB.

[2] S. Soponronarit, S. Luangmalawat, P. Prachayawarakon,S. Nathakaranakule, "Effect of Temperature on Drying Characteristics and Quality of Cooked Rice," Bangkok: Journal of Food Egineering. 2007.LWT 41, 716-723.

[3] K.D. Mustofa, "Pengaruh Waktu Pengeringan Terhadap Kadar Air Gabah Pada Mesin Pengering Gabah Kontinyu Kapasitas 100 Kg dan Daya 1890 W.UI," Jurusan Teknik Mesin Politeknik Negeri Jakarta, 2011.
[4] S. Athajariyakul and T. Leephakreeda, "Fluidized Bed Paddy Drying in Optimal Conditions Via Adaptive Fuzzy Logic Control," Bangkok: Journal of Food Engineerig.75, 104-114. 2006.

[5] N. Nusyirwan, "Kajian Pengering Gabah dengan wadah Berbentuk Silinder dan Mekanisme Pengaduk Putar, Jurnal,Cylinder Volume 1 No.2 Edisi Oktober 2014, Unika Admajaya Jakarta 2014.

[6] R. H. Perry, Chemical Engineers' Handbook Sixth Edition. USA: McGraw-Hill, 2010.

\section{NOMENKLATUR}

A, luas penampang bahan

e, emisivitas bahan.

I, kuat arus listrik 